\title{
Research on Current Control Technology of Fine Plasma Cutting Guoping $\mathrm{Li}^{1, \mathrm{a}^{*}}$, Qi Cao ${ }^{1, \mathrm{~b}}$, Yujian $\mathrm{Fu}^{1, \mathrm{c}}$ \\ ${ }^{1}$ School of Mechanical Engineering, University of Jinan, Jinan 250022, China. a727515509@qq.com, bcaoqi0707@qq.com, ${ }^{c} 1019233086 @ q q . c o m$
}

\section{Keywords: Fine plasma, Current calibration, Current PI control}

\begin{abstract}
The precision control of cutting current is the important performance index of the plasma cutting power supply, so the study of plasma cutting current control strategy have great significance. This paper first summarizes the development situation of plasma cutting power supply, and the domestic plasma power supply is mostly in the ordinary plasma stage, then, based on the characteristics of plasma arc, the volt-ampere characteristics and pulsation characteristics of the plasma arc are analyzed, the open-loop control and the closed-loop control strategy of cutting current are proposed to design the current cutting control system of the fine plasma cutting power supply, the open-loop control system is based on current calibration after cutting power supply linear test. Closed-loop control is a step response to establish power model, using PI control strategy and simulation debugging with MATLAB. Finally, the experimental results show that the cutting current PI control is superior to the open-loop control in current waveform ripple control, and the relative error can be controlled to $3.8 \%$, which greatly improves the cutting current performance of the plasma cutting power supply.
\end{abstract}

\section{Introduction}

Cutting current control is the centre of the fine plasma cutting power supply control system, cutting current is the most influential to the cutting parameters in all cutting parameters, the maximum thickness of the sheet that the system can cut and the maximum cutting speed of the system are limited by the size of the cutting current, which is the embodiment of the cutting power [1].

But at present most of the domestic plasma cutting power is still in the ordinary plasma cutting stage, or it is a simple imitation of foreign products, and domestic cutting power supply cutting current adjustment range is small, low reliability, difficult to achieve high-precision cutting requirements [2]. In this paper, the characteristics of plasma arcs which affect the stability of cutting current are analyzed. Then, two control strategies are studied, which are the current open loop control and closed loop control of the power cut current for the plasma arc characteristics.

\section{Characteristics of Plasma Arc}

Because of the plasma arc is the real load in the cutting system, the cutting quality is directly related to the characteristics of the plasma arc [3]. Plasma arc in the cutting process showed two characteristics, non-linear and arc pulse characteristics.

Nonlinear Volt Ampere Characteristics of Plasma arc. In the cutting process, the electrode of the cutting gun is connected with the cathode of the power, the workpiece is connected with the anode, and the electric field of electric arc between the cutting gun and the workpiece is nonlinear distributed, as shown in Fig. 1. It can be seen from the figure that the electric field strength in the arc length is different when the arc discharge is generated between the two electrodes. And the electric field is composed of three different field. Respectively, include the cathode pressure drop area UK, the anode voltage drop area UA and the arc column pressure drop area UC [4]. This inconsistency of the electric field is reflected in the different impedance of three areas. From the 
diagram is not difficult to see the minimum pressure drop is the arc column area, so the minimum impedance is here, and relatively, the voltage drop and impedance of the two poles is large.

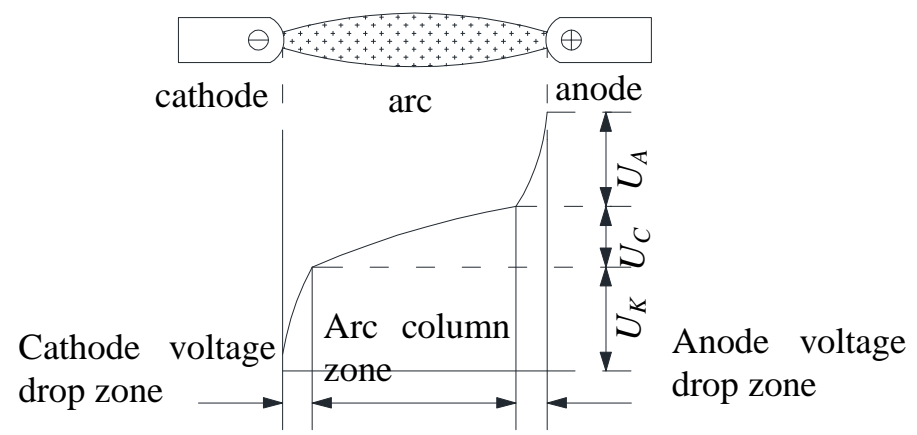

Fig. 1 Distribution of arc voltage drop.

From the above analysis, it can be known that the characteristic of the voltage of the load is nonlinear. In the cutting process, because of thickness of the plate is not uniform and the interference caused by machine accuracy and environmental changes, the change of cutting load is inevitable. In the whole cutting process, the random load will affect the real-time changes of cutting power circuit structure parameters, making the power system show the characteristics of time-varying when it output current.

Characteristics of Plasma Arc Pulsation. During the cutting process, the arc pressure of the plasma arc will be pulsating, and there are three basic modes, such as stable mode, takeover mode and reburn mode, as shown in Fig. 2. It is not difficult to see from the diagram that in the reburn mode, arc voltage amplitude is large and the waveform was jagged, arc stability is poor. Under the takeover mode, the arc is stable, and the fluctuation is obvious, basically showing a sinusoidal variation change. In the stable mode, the fluctuation characteristic is weakest and approximate a straight line, it is relatively stable in this mode, and the arc pressure is smaller [5].

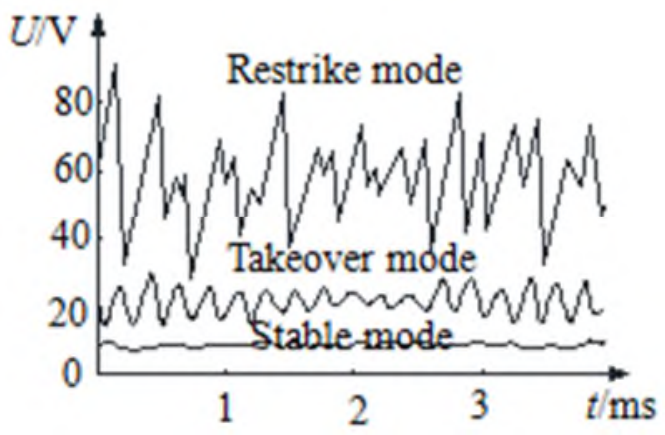

Fig. 2 Arc pulse mode diagram.

The pulsation characteristic is more obvious with the increase of the current. If the cutting current is not limited, the phenomenon of "double-arc" will occur. Therefore, the pulsation characteristics can be effectively controlled, and its control in the stable mode, so as to effectively improve the quality of the system.

\section{Study on Cutting Current Control Strategy}

The plasma arc has nonlinear and high frequency characteristics, and there is a current ripple during the cutting process, after analyzing the structural properties of the cutting system and the cutting process requirements, this paper adopts OMRON CP1H PLC as the controller, the open-loop control and closed-loop control of the cutting current of the fine plasma cutting power are compared, the structure of the current control system is shown in Fig. 3. 


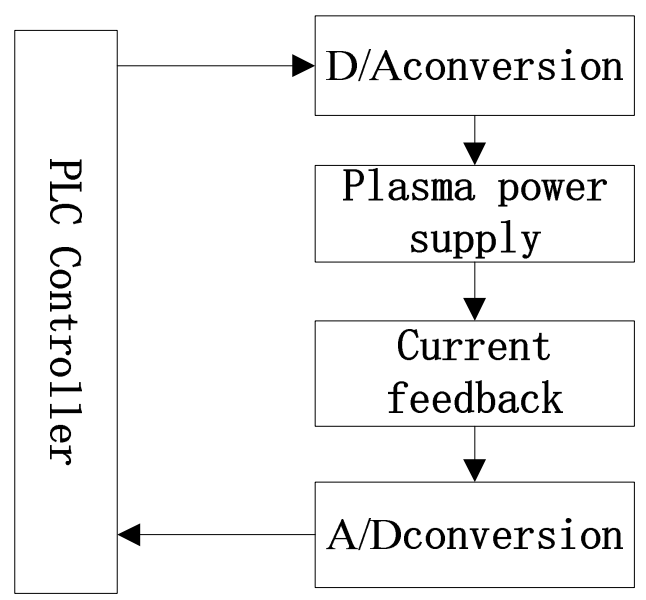

Fig. 3 Current control system structure.

\section{Cutting Current Open Loop Control.}

Study on characteristics of plasma power supply. In order to achieve the effect of the precise adjustment, need to detect output characteristic of the plasma power, one of the most important is the power of linear detection. First of all, in the open-loop state without feedback regulation, the plasma cutting power supply is shorted to the positive and negative, and directly through the PLC D/A given plasma power supply current output, measured in the circuit corresponding to the digital output of the actual output current value. In order to eliminate the accidental fluctuation of the current and reduce the influence of electromagnetic interference, this system adopts the average filter, for each sampling point sampling 3 times, and take its average as the sampling values of each sample point, scilicet $x_{i}=\frac{x_{1}+x_{2}+x_{3}}{3}$ the test data are shown in table 1 .

Table 1. Plasma power supply linear test.

\begin{tabular}{cccccc}
\hline Value Digital & 500 & 1000 & 1500 & 2000 & 2500 \\
\hline Group 1 & 35.2 & 68.7 & 101.3 & 133.1 & 168.0 \\
Group 2 & 34.5 & 67.0 & 100.2 & 132.1 & 166.8 \\
Group 3 & 36.4 & 69.5 & 103.1 & 134.8 & 169.2 \\
$\begin{array}{c}\text { Average } \\
\text { value }\end{array}$ & 35.4 & 68.4 & 101.5 & 133.3 & 168.0 \\
\hline
\end{tabular}

From the correlation analysis, the linear correlation between the two variables commonly used correlation coefficient $\rho_{x y}$ to represent [6], Table 1 plasma power supply test data into the formula to get the plasma power output linearity:

$$
\rho_{x y}=\frac{E\left[\left(x-\mu_{x}\right)\left(y-\mu_{y}\right)\right]}{\sigma_{x} \sigma_{y}} \approx 99 \%
$$

Study on cutting current calibration of plasma cutting power supply. Plasma cutting current is given by the operator selected cutting current and then converted into the corresponding digital set to the PLC's D/A module, and then D/A output to the plasma power supply chopper control current output. Therefore, the first need to calibrate the cutting current, this paper uses the least square method to calibrate the plasma power supply, improve the accuracy of the current open-loop control, the structure of the control system is shown in Fig. 4. 


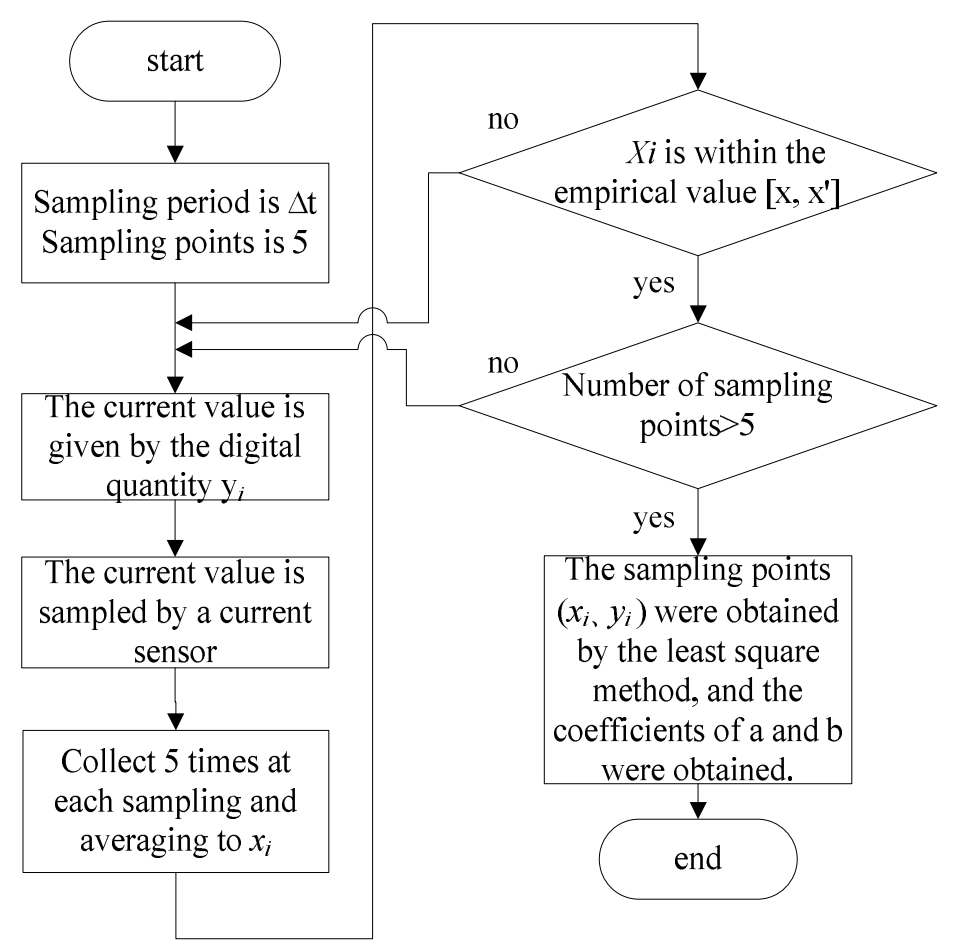

Fig. 4 Current calibration control block diagram.

Calculate the coefficient $a, b$, the establishment of a linear relationship for the $y=a x+b$, that is, cutting the current engineering quantity to digital conversion relationship, the cutting current calibration is complete.

Cutting Current Closed Loop Control. The system is controlled by the plasma cutting power supply, the current sensor detects the output current signal as a negative feedback signal input, adjustment of cutting current through PI controller, can make real-time response to external disturbances, and realize the servo control, timely adjustment of cutting current and improve the stability of cutting current waveform, ensure the cutting quality control system structure shown in Fig. 5.

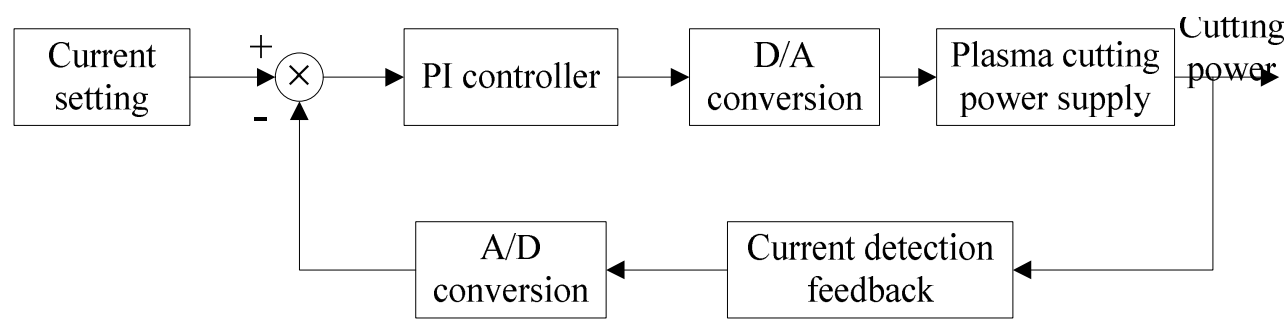

Fig. 5 Plasma cutting current control system structure.

The establishment of fine plasma current control object. In this paper, the output response characteristics of the plasma power supply are observed. It is found that the power supply can be expressed as a first order inertial pure lag link, and the transfer function can be expressed as:

$$
G(s)=\frac{K}{T s+1} \mathrm{e}^{-\tau s}
$$

In the formula: $K$-The static gain of the object; $T$-The time constant of the subjects; $\tau$-The lag time constant for the object;

$\mathrm{K}, \mathrm{T}, \tau$ is determined by the step response curve method, this method is based on the step response curve of the system to be solved by the method of plot, as shown in Fig. 6. 

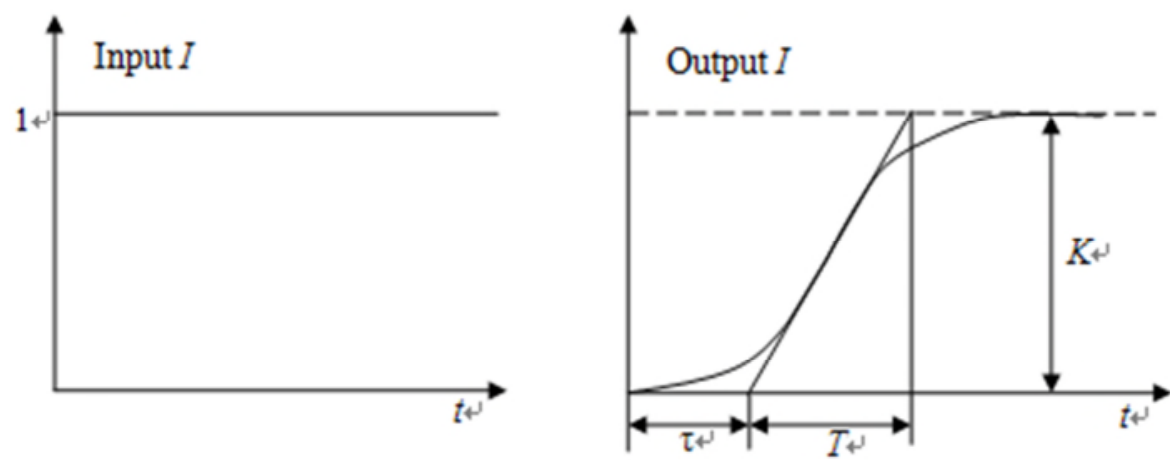

Fig. 6 The unit step response curve method.

First, the plasma power input step signal, using the oscilloscope acquisition response curve, and then use the mapping method to calculate the approximate coefficient, plasma power current step response curve shown in Fig. 7.

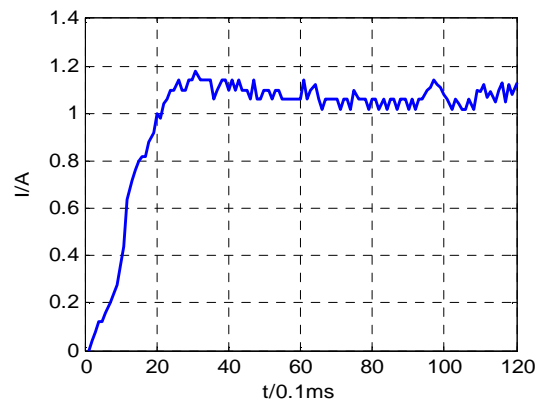

Fig. 7 Step response curve.

The drawing method of drawing 6 can be obtained from the graph 7: $K=1.1, T=20, \tau=10$, so the transfer function of the plasma power supply is approximately:

$$
G(s)=\frac{1.1}{20 s+1} \mathrm{e}^{-10 s}
$$

Control parameter setting. This paper firstly uses the Ziegler-Nichols [7] tuning method, according to the $\mathrm{K}, \mathrm{T}, \mathrm{t}$ value, and in accordance with the empirical formula to calculate the parameters of the PID controller, scilicet $K_{p}=1.64, T_{i}=30, T_{d}=0$.

In order to establish the approximate model of the plasma power supply for the controlled object, with the help of MATLAB software in the Simulink plug-in simulation testing of the plasma power supply control system of PI, firstly, the whole simulation model of the plasma power cutting current PI control system is established by using the function library module, as shown in Fig. 8.

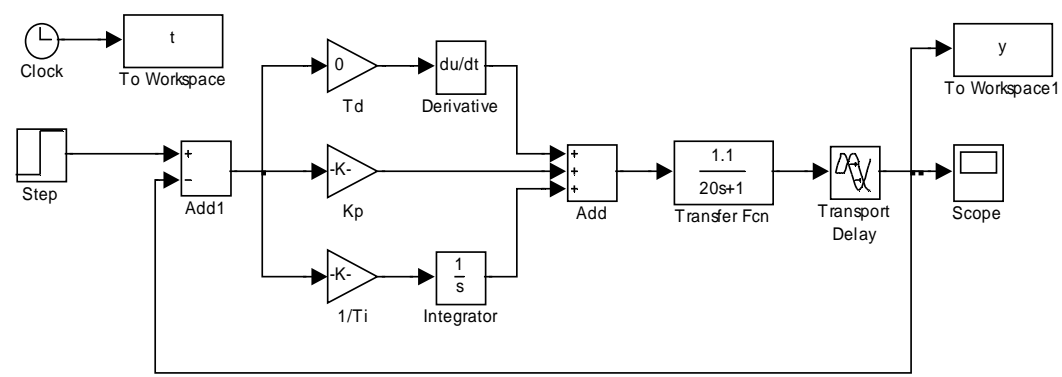

Fig. 8 Simulation model of plasma cutting current PID control system.

The parameters obtained by the Ziegler-Nichols method are input to the simulation model of the plasma cutting current PID control system shown in Fig. 6. After constant debugging PI controller parameters, cutting current set 130A, run simulation, the simulation results in Fig. 9 Figure. 


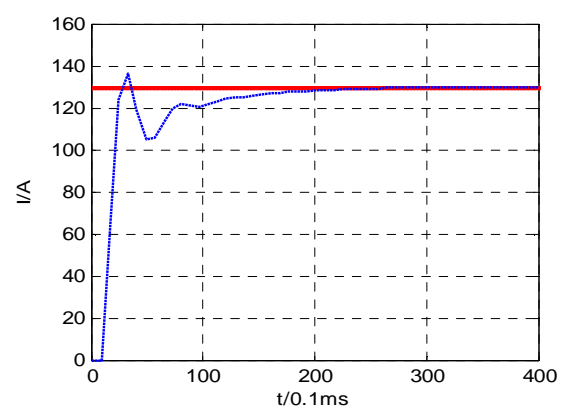

Fig. 9 The cutting current PI controls the simulation waveform.

\section{Experimental Results and Analysis}

The cutting current is collected by using the oscilloscope to detect the power of the fine plasma cutting through the current sensor. The experimental device is shown in Fig. 10.

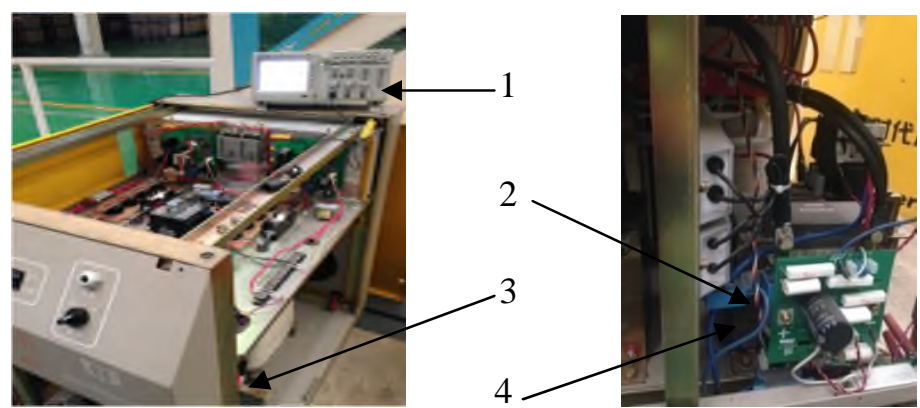

1. Oscilloscope 2. current sensor (cutting) 3. Plasma power supply 4. current sensor (Arc - starting) Fig. 10 Cutting current acquisition diagram.

The oscilloscope to detect the current sensor voltage value into the actual cutting current value, the production of open-loop control cutting current curve shown in Fig. 11, PI control cutting current curve shown in Fig. 12.
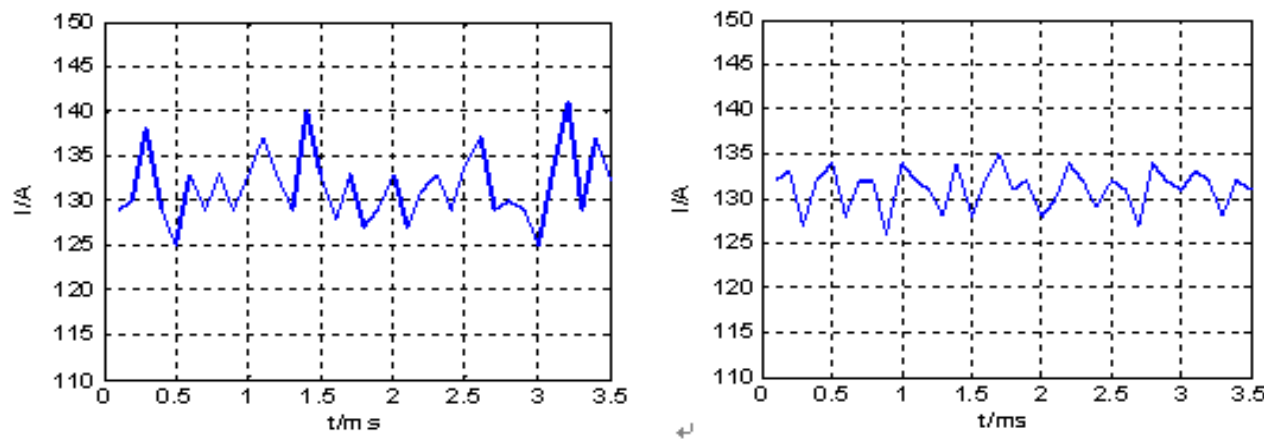

Fig. 11 Cutting current open loop. Fig. 12 The cutting current PI controls the test waveform test waveform

Analysis and calculation of Fig. 11 and Fig. 12 cutting current test waveform, obtained plasma cutting power supply current test performance parameters, as shown in Table 2.

Table 2. Cutting current test parameters.

\begin{tabular}{ccccc}
\hline Mode & Current range /A & Average value /A & $\begin{array}{c}\text { Peak-to-peak } \\
\text { value }\end{array}$ & Relative error \\
\hline Open-loop & $126 \sim 142$ & 132.60 & 12 & $9.2 \%$ \\
PI control & $126 \sim 135$ & 131.11 & 9 & $3.8 \%$ \\
\hline
\end{tabular}


From the current test waveforms and cutting current test parameters Table 2, we can see that the current open loop control of the current fluctuation is larger, the average value is higher, and the maximum relative error is larger. This is mainly due to the output current ripple caused by the anode spot, and the change of the arc physical characteristics due to the precision of the machine tool. Compared with the open-loop control, the cutting current PI control has obviously improved the control precision and the waveform quality, because the cutting current PI control system has been in the dynamic regulation process, and the PI regulation can realize the stepless adjustment, especially is the integral part of the cutting power control system can reduce the static difference, after adjustment, the average current value has been improved closer to the set current, and the current waveform quality improved significantly.

\section{Summary}

By studying the characteristics of the plasma arc, the paper analyzes the nonlinear volt-ampere characteristic and the fluctuating characteristics of plasma arc on the fluctuation of cutting current, two strategies are proposed for the current calibration of open loop control and current PI closed loop control, the experimental results show that the precision and the quality of the PI control are much better than those of the open-loop control, and the relative error of the cutting current fluctuation can be controlled within $3.8 \%$, greatly improve the cutting current control effect, to achieve a fine plasma cutting power supply cutting current control requirements, so the PI control is more suitable for fine plasma cutting power cutting current control strategy.

\section{Acknowledgements}

This paper was supported by the Foundation for Outstanding Young Scientist in Shandong Province, Granted No. BS2015NJ009

\section{References}

[1] C. S. Wang. Research on control technology of inverter plasma arc cutting power supply. Harbin: Harbin University of Science and Technology, 2012.

[2] J. S. He. Development of full digital inverter plasma arc cutting power supply. Harbin: Harbin University of Science and Technology, 2011.

[3] C. Y. Zhang. Modeling and control of inverter plasma cutting power supply. Xi'an: Xi'an University of Technology, 2014.

[4] F. J. Zhang. Study on all digital inverter plasma arc cutting power supply. Harbin: Harbin University of Science and Technology, 2009.

[5] Z. Duan, J. Heberlein. Arc instabilities in a plasma spray torch. J. Therm. Spray Tech. 11(1) (2000) 44-51.

[6] S. B. Xiong, C. Y. Huang. Mechanical engineering testing technology foundation. Beijing: Machinery Industry Press, 2006, pp. 162.

[7] J. G. Ziegler, N. B. Nichols. Optimum Settings for automatic controllers. Trans. ASME, 64(11) (1942) 759-768. 